\title{
Opinions of Caring Professionals on Satisfying of Spiritual Needs in Palliative Care
}

\author{
M. Kopacikova (Maria Kopacikova)', K. Zrubakova (Katarina Zrubakova)², \\ I. Bartosovic (Ivan Bartosovic) ${ }^{2}$
}

${ }^{1}$ Catholic University Ruzomberok, Slovakia.

${ }^{2}$ St. Elizabeth University of Health and Social Work, Bratislava, Slovakia.

\section{E-mail address:}

maria.kopacikova@ku.sk

\section{Reprint address:}

Maria Kopacikova

Faculty of Health, Catholic University

Nám. A. Hlinku 48

03401 Ruzomberok

Slovakia

Source: Clinical Social Work and Health Intervention

Pages: $50-59$

Volume: $10 \quad$ Issue: 3

Cited references: 21

\section{Reviewers:}

Jirina Kafkova

Nairobi, St. Bakitha Clinic, KE

Zofia Szarota

Pedagogical University of Cracow, PL

\section{Keywords:}

Palliative Patient. Needs. Spiritual Needs. Assessment. Nursing care.

\section{Publisher:}

International Society of Applied Preventive Medicine i-gap

CSWHI 2019; 10(2): 50 - 59; DOI 10.22359/cswhi_10_3_09 @ 2019 Clinical Social Work and Health Intervention

\section{Abstract:}

We have identified healthcare professionals as assessing spiritual needs, comparing respondents' answers and finding differences. The investigated sample contained 447 respondents (nurses and other people delivering health care service). We used the anonymous SNAP questionnaire method. The data obtained were processed using one-dimensional 
descriptive statistics. We have statistically tested the hypotheses of our research using inductive statistics in IBM SPSS Statistics 20 (Statistical Package for Social Sciences). For the influence of independent variables on dependent variables, one-factor scattering analysis in the form of a One-Way ANOVA test was used as part of the parametric tests. To determine the correlation coefficient we used a parametric test in the form of a Bravais-Paerson Test.

According to the answers, the average score in the domain of psychosocial needs was 3,24922 and in the spiritual needs domain 3,22836. In assessing the relationship between gender, age, occupation, practice, religion, and spiritual judgment, we have been shown to have a linear relationship. We are proposing to continuously increase and supplement the knowledge of health professionals by attending seminars and training on spiritual needs and current trends in their assessment.

\section{Introduction}

Human life can be seen as a set of events that are closely interconnected; that change and influence people throughout their lives until death. However, the dying period and death continue to be a taboo in society today. Men are the only living creatures aware of their mortality, which is accompanied by anxiety, fear and uncertainty. The 21 st century with its rapid development in the field of medicine has also contributed significantly to a negative perception of life. As people lost contact with primary events of life, they got a false feeling that death doesn't concern them. Care for a dying person is a very responsible and demanding job. The process of dying means decompensation, gradual weakening and emotional pain.

In situations where the treatment is ineffective, palliative care seems to be one of the humane alternatives. The purpose of palliative care is to ensure for those who, unfortunately, can no longer be helped by modern medicine, at least high-quality of their last moments of life. Satisfaction of needs also contributes to adequate quality of life of the terminally ill. In addition to biological needs, spiritual needs also dominate in the life of a dying person.

\section{Palliative Care}

Palliative care has indivisible medical-social inter-sector dimension, and that is why we are here also looking for ways of its meaningful implementation in the services for the individuals reliant on social assistance. This is a modified definition of palliative care by the World Health Organization from 2002: "Palliative care is understood as an approach that improves quality of life of the patients and their families facing the problems associated with life threatening illness by means of prevention and relief from pain, achieved through assessment and treatment of pain and other problems of physical, psychosocial and spiritual nature" (Frankl, 2010). This is achieved through its early detection, correct and perfect assessment, treatment of pain and other physical, psychosocial and spiritual problems (Munzarova, 2005, p. 61-62). A palliative approach respects all needs of a dying person which are significantly different from those of a patient with a favourable diagnosis. Family is an important part of this. It can effectively help the patient, particularly with the emotional state. However, family also needs care and receives this care during the end of life assistance of the patient as well as after patient's death (Haskovcova, 2000, p. 36-37). 


\section{Spiritual Care}

Humans are bio- psycho- social- spiritual beings. Besides natural needs, humans have the need for the supernatural, because they are spiritual beings. Definition and specification of the word spirituality is difficult, as spiritual dimension is not based on rational thinking and cannot be strictly proved. Spirituality is the object of study of several fields: philosophy, theology, psychology, social work, nursing... Its interpretations in the mentioned fields are different.

In philosophy, spirituality refers to the existential attitude of a person, overall experience related to the transcendence sphere which can be religious or non-religious (Strizenec, 2005).

In theology, it includes belief in God, a higher power (Hamer, Copeland, 2003). In relation to psychology of personality, spiritual dimension of a personality transcends mundane life and opens to formation of characteristics such as love, responsibility, foresight, wisdom, serenity and nobility. In nursing, the most comprehensive definition is the one by Farsky et al. (2010, p.34) ... ,spirituality is a universal dimension of the human existence, and it reflects experience and expression of the human spirit in a unique and dynamic process. Spirituality integrates, develops and strengthens a person, family, community, and enables and gives strength for finding of a meaning and purpose in life, finding of hope, forgiveness, even in the time of crisis, illness or expectation of death. Culture, religiosity or historical context are not conditions to religiosity, but they might affect how spirituality of a person, family, community is manifested externally in everyday life".

Spiritual needs are a part of human personality, they are classified in the category of higher needs. They are divided into three basic areas, which are:

- needs related to self-awareness (need for hope, love, purpose and meaning of life, etc.),
- needs related to others (need for forgiveness, acceptance of the loss of love, respect from others, etc.),

- needs related to the absolute (need for certainty of God existence, belief, etc.).

In the provision of nursing care, assessment is a complex bio-psycho-social-spiritual evaluation of the patient; respects all particularities of age; focuses on the needs that have been modified or added due to age and illness. The needs are identified using formal (questionnaires, structured interview); informal tools (patient observation, verbal and non-verbal communication); as well as information about perception of the illness by the relatives.

Obtaining of spiritually history is also important- most frequently through a discussion about one's belief and life values (Buck, McMilan, 2012). Spiritual needs may not always be associated with life satisfaction, but sometimes with anxiety, and can be interpreted as a patient's desire for spiritual well-being. The need for peace, health and well-being are universal human needs and are particularly important for patients with long-term illnesses (Kober, 2015).

In order to identify spiritual needs of a patient, the nurse should have long-term contact with the patient and form a relationship of trust with the patient. In the environment of the Slovak Republic, in practice we most frequently use informal tools - we obtain the information through dialogue and observation. A dialogue on these subjects usually takes place only after the nurse has gained the trust of the patient and the patient is sure that he/ she is understood.

Clinical assessment of spiritual aspects of a patient focuses on identification of impaired or non-functional spirituality, the reasons for which are related to self-image and self-evaluation. It is necessary to identify patient's 
concerns, reasons for those concerns, and how we can help the patient cope with them. A valuable source of information can be observation of patient's behaviour. Whether the patient prays before meals or at another time; frequent feelings of sadness; whether the patient has sleeping problems; speaks inappropriately; expresses anger". "What have I done to deserve this?" Sudden change of routine, of patient's behavior, tells us about patient's spiritual distress. Attention must be paid particularly to expressions of self-blame and to understanding of the illness as punishment. Of importance is also information about patient's goals and expressions of belief. When assessing religiosity, mature attitude can be indicatively defined as full acceptance of the content of a religious belief and action based on that belief.

We identify support systems and their importance for the patient. We also focus on the relationship of patients with their fellow patients, nurses and other medical professionals.

The assessment also includes information about the current medical condition. We evaluate whether the illness is acute or chronic; the stage of the illness; its prognosis. Of high importance is to assess patient's informedness; expectations; emotional state; patient's interpretation of the illness. We also assess patient's own activities and options in dealing with the difficult situation. We also focus on obtaining information about the patient's experience and on expressions of moral distress and conflict.

\section{Assessment of Spiritual Needs in Clinical Practice}

In the previous text we presented the possibilities of assessment of spirituality and spiritual needs in terminally ill patients. We wanted to know how medical workers in the Slovak Republic and the Czech Republic see the spiritual needs of patients, how much the patients need help and what differences are there in respondents' assessments.

\section{Methodology and Description of the Research Sample}

The empirical study was carried out in the form of applied research in medical care facilities. The research was carried out in the period of 2016 - 2017. On the basis of the established objectives, we chose the empirical method of data collection - questionnaire The Spiritual Needs Assessment for Patient (SNAP) constructed by R.K. Sharma. (Sharma, 2012), which made it possible to objectively illustrate the reality of the studied indicator. The questionnaire was distributed on-line via links on one Slovak and one Czech website. The research sample consisted of 447 respondents.

We processed the collected data into an MS Excel 7.0 spreadsheet and we carried out first level classification. When analysing the research data, as the first step we processed the collected data using the method of one-dimensional descriptive statistics (one way ANOVA). After the classification we calculated the absolute and the relative frequency and we created frequency spreadsheets for the observed indicators. The statistical processing was carried out using inductive statistics. For further processing of the collected statistical data and its subsequent use in verification we used other statistical methods, such as: analysis of variance, correlation, multiple range analysis, $\mathrm{t}$ - statistical test, ANOVA. For the actual calculation and presentation of the results in this work we used statistical software Statistica in the version X.

\section{Research Sample}

The research sample consisted of 447 respondents providing care for patients in a medical care facility at the time of the research. Of the total number of respondents in the research 
sample, the most represented group, with respondent number of $400(89.46 \%)$, was the group of female respondents. Male respondent number was 47 (10.49\%). Of the total number of the respondents, $84.34 \%$ (377) were nurses. Other medical professionals were represented in the research sample in the number of $15.66 \%$ (70), of which the largest representation was that of paramedical personnel $6.26 \%$ (28). The largest representation of $183(40.55 \%)$ was that of nurses and medical professionals in the age category of 35-44. The largest representation of $144(32.21 \%)$ was that of nurses and medical professionals with experience of 1021 years. Of the entire research sample of 447 respondents, $342(76.51 \%)$ claimed to be religious. Other characteristics of respondents are in the tables 1-3.

Table 1: Age of respondents

\begin{tabular}{|c|c|c|}
\hline $\begin{array}{c}\text { Age } \\
\text { category }\end{array}$ & $\begin{array}{c}\text { absolute } \\
\text { number } \\
\mathbf{n}\end{array}$ & $\begin{array}{c}\text { percentage } \\
\mathbf{\%}\end{array}$ \\
\hline $25-34$ & 127 & 28.43 \\
\hline $35-44$ & $\mathbf{1 8 3}$ & $\mathbf{4 0 . 5 5}$ \\
\hline $45-54$ & 105 & 23.55 \\
\hline $55-64$ & 32 & 7.47 \\
\hline $\begin{array}{c}\text { Total } \\
\text { number }\end{array}$ & $\mathbf{4 4 7}$ & $\mathbf{1 0 0}$ \\
\hline
\end{tabular}

Table 2: Length of respondents' professional experience

\begin{tabular}{|l|c|c|}
\hline $\begin{array}{c}\text { Length of } \\
\text { professional } \\
\text { experience }\end{array}$ & $\begin{array}{c}\text { absolute } \\
\text { number } \\
\text { n }\end{array}$ & $\begin{array}{c}\text { percentage } \\
\mathbf{\%}\end{array}$ \\
\hline $\begin{array}{l}\text { less than } \\
\text { 5 years }\end{array}$ & 60 & 13.42 \\
\hline 5-9 years & 69 & 15.44 \\
\hline 10-21 years & $\mathbf{1 4 4}$ & $\mathbf{3 2 . 2 1}$ \\
\hline 22 to 31 years & 115 & 25.73 \\
\hline over 31 years & 59 & 13.20 \\
\hline $\begin{array}{l}\text { Total } \\
\text { number }\end{array}$ & $\mathbf{4 4 7}$ & $\mathbf{1 0 0}$ \\
\hline
\end{tabular}

Table 3: Religion of respondents

\begin{tabular}{|l|c|c|}
\hline \multicolumn{1}{|c|}{ Religion } & $\begin{array}{c}\text { absolute } \\
\text { number } \\
\mathbf{n}\end{array}$ & $\begin{array}{c}\text { percentage } \\
\mathbf{\%}\end{array}$ \\
\hline religions & $\mathbf{3 4 2}$ & $\mathbf{7 6 . 5 1}$ \\
\hline non-religions & 49 & 10.96 \\
\hline atheists & 16 & 3.58 \\
\hline agnostics & 5 & 1.12 \\
\hline No response & 35 & 7.83 \\
\hline $\begin{array}{l}\text { Total } \\
\text { number }\end{array}$ & $\mathbf{4 4 7}$ & $\mathbf{1 0 0}$ \\
\hline
\end{tabular}

\section{Result Analysis}

The results obtained in the questionnaire are demonstrated in the form of table. The individual questionnaire items were answered by all 447 respondents. The variation range of the answers was from the maximum of 4 to the minimum of 1 ( $4=\mathrm{a}$ lot, $3=$ a little, $2=$ little, $1=$ not at all).

In the domain of psycho-social needs we were interested in patients' need for assistance. The respondents' answers in the individual items were in the range from 4 (patient needs help a lot) to 1 (patient doesn't need help at all), the highest average number 3.4 (patient needs help a little) was found when asking about sharing of thoughts and feelings with friends and family and about concern for the family, which indicates strong attachment of patients to their friends and family. More detailed description in Table no. 4. 
Table 4: Psychosocial needs n 447

\begin{tabular}{|c|c|c|c|c|c|c|c|}
\hline & average & SD & maximum & minimum & variance & $\begin{array}{c}\text { absolute } \\
\text { deviation }\end{array}$ & SD \\
\hline A & 3 & 3 & 4 & 1 & 0.70 & 0.6 & 0.84 \\
\hline B & 3.1 & 3 & 4 & 1 & 0.66 & 0.6 & 0.81 \\
\hline C & 3.3 & 3 & 4 & 1 & 0.51 & 0.6 & 0.71 \\
\hline D & 3.4 & 4 & 4 & 1 & 0.52 & 0.6 & 0.72 \\
\hline E & 3.4 & 4 & 4 & 1 & 0.51 & 0.6 & 0.72 \\
\hline
\end{tabular}

Legend: a- connection with other patients with the same illness, b- relaxation and stress management, c- learning to cope with sadness, $d$ - sharing of thoughts and feelings with friends and family, e- concern for the family

In the domain of spiritual needs, the answers were in the range from 4 (patient needs help a lot) to 1 (patient doesn't need help at all). We found that patients need a little help with looking for meaning in the illness experience, with looking for hope and overcoming fear, where the highest average value was 3.5 (patient needs help a little to a lot). A more detailed description of the individual items is in Table no. 5.

Table 5: Spiritual needs n 447

\begin{tabular}{|c|c|c|c|c|c|c|c|}
\hline & average & SD & maximum & minimum & variance & $\begin{array}{c}\text { absolute } \\
\text { deviation }\end{array}$ & SD \\
\hline a & 3.5 & 4 & 4 & 1 & 0.47 & 0.6 & 0.68 \\
\hline $\mathbf{b}$ & 3.5 & 4 & 4 & 1 & 0.44 & 0.6 & 0.66 \\
\hline $\mathbf{c}$ & 3.5 & 4 & 4 & 1 & 0.42 & 0.6 & 0.65 \\
\hline $\mathbf{d}$ & 2.9 & 3 & 4 & 1 & 0.67 & 0.6 & 0.82 \\
\hline $\mathbf{e}$ & 3 & 3 & 4 & 1 & 0,70 & 0.6 & 0.83 \\
\hline $\mathbf{f}$ & 3.1 & 3 & 4 & 1 & 0.68 & 0.6 & 0.83 \\
\hline $\mathbf{g}$ & 3.2 & 3 & 4 & 1 & 0.45 & 0.6 & 0.67 \\
\hline $\mathbf{h}$ & 3.3 & 3 & 4 & 1 & 0.63 & 0.7 & 0.79 \\
\hline $\mathbf{c h}$ & 3.4 & 4 & 4 & 1 & 0.58 & 0.7 & 0.76 \\
\hline $\mathbf{i}$ & 3.4 & 3 & 4 & 1 & 0.49 & 0.6 & 0.70 \\
\hline $\mathbf{j}$ & 3 & 3 & 4 & 1 & 0.72 & 0.6 & 0.85 \\
\hline $\mathbf{k}$ & 3.2 & 3 & 4 & 1 & 0.78 & 0.7 & 0.89 \\
\hline $\mathbf{l}$ & 3 & 3 & 4 & 1 & 0.75 & 0.6 & 0.86 \\
\hline
\end{tabular}

Legend: a- looking for meaning in the illness experience, b- looking for hope, c- overcoming fear, $d$ personal meditation or prayer, e- relationship with god or something bigger than myself, f- becoming closer to the community which shares your spiritual beliefs, g- coping with any kind of pain, $h$ - meaning and purpose of life, ch-death and dying, i- looking for peace, d- correction of old conflicts, pain, family grudges or grudges between friends, j- looking for forgiveness, $\mathrm{k}$ - making decisions about the treatment that are in accordance with your spirituality and religious belief. 
In Table no. 6 we present the score in the psychosocial and the spiritual domain. We found that the average answer in the domain of psychosocial needs was 3.24922 and the median answer value was 3.33 (patient needs help a little). The answers were in the range from 1 (patient doesn't need help at all) to 4 (patient needs help a lot). The average answer was 3.22836 and the median answer value was 3.30, patient needs help a little.

\section{Discussion}

The purpose of palliative care is to ensure the highest possible quality of life; to respect and protect dignity of terminally ill patients; to thoroughly base the care on wishes and needs of the patients as well as to protect and respect the patient's family. Good quality care must include complex perception and satisfaction of needs of patients and their families. Palliative care includes not only medical

Table 6: Needs - score n 447

\begin{tabular}{|c|c|c|c|c|c|c|c|c|}
\hline Needs & average & SD & maximum & minimum & variance & $\begin{array}{c}\text { absolute } \\
\text { deviation }\end{array}$ & SD & Median \\
\hline $\begin{array}{c}\text { Psycho- } \\
\text { social }\end{array}$ & 3.24922 & 3.4 & 4 & 1 & 0.31 & 0.45562 & 0.56 & 3.33 \\
\hline Spiritual & 3.22836 & 3.31 & 4 & 1 & $0 \ldots 2$ & 0.448767 & 0.56 & 3.30 \\
\hline
\end{tabular}

On the basis of the statistical processing of the results we present how sex, age, occupation, experience and religion are mutually related in the assessment of patients' spiritual needs. When comparing the assessments of patients' needs we examined whether there is a statistically significant relationship between assessment of patients' needs and the individual variables. For the identification of the relationship we used Bravais-Pearson correlation coefficient. This correlation coefficient is the degree of strength of linear statistical dependency of two numeric variables. We set the statistical significance level to 0.01 error probability and we used it to compare the achieved statistical significance. We found that there is a statistically significant relationship $(\mathrm{P}<0.05)$ between sex and age of the respondents and between religion and the length of experience. Statistically significant relationship $(\mathrm{P}<0.01)$ exists between sex and occupation, length of experience and religion, between length of experience and sex, age and occupation. The score of assessment of psychosocial needs and the score of spiritual needs showed a significant relationship $(\mathrm{P}<0.01)$ (Table no. 7). care provided by a doctor, but also provision of nursing care, rehabilitation, mental health care, spiritual care and social counseling (Sláma et al., 2007).

Spiritual care should be a lot more conscious and purposeful part of the role of a large assistance team (Faull et al., 2012).

The main objective of the work was to examine how medical professionals in the context of nursing care assess spiritual needs of the patients. Assessment is a complex biopsycho-social-spiritual evaluation of the patient, it respects all particularities of age and it focuses on the needs that have been modified or added due to age and illness. It requires a long-term contact with the patient and establishment of relationship of trust. Hermann (2007) states that nurses/medical professionals must recognize the importance of spirituality and religiosity for the patient, and only assessment of specific spiritual needs can lead to planning of interventions for their satisfaction.

We found that, within the psychosocial domain of spiritual needs, what patients need the 
Table 7: Relation with the categorizing items (Pearson Correlation) n 447

\begin{tabular}{|c|c|c|c|c|c|c|c|c|}
\hline & & Sex & Age & Profession & Practice & Religion & $\begin{array}{c}\text { Score } \\
\text { A } \\
\end{array}$ & $\begin{array}{c}\text { Score } \\
\text { B }\end{array}$ \\
\hline \multirow{2}{*}{ Sex } & Pearson & 1 & $\begin{array}{c}-.114 \\
*\end{array}$ & $.228 * *$ & $-71 * *$ & $145^{* *}$ & -.70 & -.72 \\
\hline & Sig. & & .015 & .000 & .000 & .002 & .138 & .128 \\
\hline \multirow{2}{*}{ Age } & Pearson & $\begin{array}{c}-.114 \\
*\end{array}$ & 1 & -.008 & $.656^{* *}$ & .018 & .036 & .052 \\
\hline & Sig. & .015 & & .868 & .000 & .97 & .444 & .275 \\
\hline \multirow{2}{*}{$\begin{array}{l}\text { Profes- } \\
\text { sion }\end{array}$} & Pearson & $\begin{array}{c}.228 \\
* *\end{array}$ & .008 & 1 & $-.161 * *$ & -.009 & -.035 & -.033 \\
\hline & Sig. & .000 & .868 & & .001 & .854 & .462 & .481 \\
\hline \multirow{2}{*}{ Practice } & Pearson & $\begin{array}{c}-.171 \\
* *\end{array}$ & $\begin{array}{l}.656 \\
* *\end{array}$ & $-.161 * *$ & 1 & $.114^{*}$ & .037 & .043 \\
\hline & Sig. & .000 & .000 & .001 & & .016 & .430 & .365 \\
\hline \multirow{2}{*}{ Religion } & Pearson & $\begin{array}{l}.145 \\
* *\end{array}$ & .018 &,- 009 & $.114^{*}$ & 1 & -.068 & -.079 \\
\hline & Sig. & .002 & .697 & .854 & .016 & & .148 & .094 \\
\hline \multirow{2}{*}{ Score A } & Pearson & -.070 & .036 & -.035 & 037 & -.068 & 1 & $.600 * *$ \\
\hline & Sig. & .138 & .444 & .462 & .430 & .148 & & .000 \\
\hline \multirow{2}{*}{ Score B } & Pearson & -.072 & .052 & -.033 & .043 & -.079 & $\begin{array}{c}.600^{*} \\
*\end{array}$ & 1 \\
\hline & Sig. & .128 & .275 & .481 & ;365 & .094 & .000 & \\
\hline
\end{tabular}

Legend: ** Correlation is significant at the 0.01 level (2-tailed).

* Correlation is significant at the 0.05 level (2-tailed).

most help with is sharing of ideas and feelings with their friends and family and concern for the family (average answer 3.4), which indicates strong attachment to friends and family. The total average number in the psychosocial needs domain was 3.24922, the answer median value was 3.33 . For the patient it is important to have social contact, support, interest by the personnel, adequate communication and information (Lukackova, 2012). Quality assistance can be provided by someone who is ready for this role, who has an understanding of their own mortality (Moraucikova, Lazarova, 2015).

With regard to assessment and satisfaction of needs in the spiritual needs domain, patients need a little help to a lot of help with looking for meaning in the illness experience, with looking for hope and with overcoming of fear (the average of 3.5). The average answer was 3.22836 and the median answer value was 3.30. When patients need to create the conditions for coping with matters of their inner world and they cannot do it on their own, we must help them. To call the person they need sometimes it is friends and family, sometimes a spiritual teacher or a mental health specialist. An accompanying priest helps with his presence and listening. He reflects the values he supports in his own life (Hatokova et al., 2009). A dying person with fulfilled spiritual needs and resolved spirituality is poised and has a peace of mind, has no conflicts with others, is able to accept the pain and suffering, has come to terms with death and exudes harmony and hope (Malikova, 2011).

In the process of disease and dying, staff and patients are brought into interaction. In 
today's modern nursing care, high emphasis is placed on the quality of care provision and humanization (Andrasi et al., 2017). In order to be able to effectively identify patient's spiritual needs, medical professionals need to have sufficient experience and relatively good basic knowledge in the field of psychology, ethics, communication and theology as well as personal interest in people. There is a statistically very significant relationship between sex and occupation, length of experience and religion, between length of experience and sex, age and occupation. The score of assessment of psychosocial needs and the score of spiritual needs also showed a very significant relationship (Table no. 7)

Assessment in palliative nursing care is a systematic and continuous collection of data of patients (family, friends) with a terminal, time-limited illness, their ability to carry out everyday activities, the effect of pain and other symptoms on satisfaction of biological, psychosocial and spiritual needs, patient's (family's) expectations and support possibilities. It must be continuous and dynamic in view of the patient's condition, progress of the illness and sudden changes, age, current medical condition, personal characteristics, value preferences, social background of the patient (of the family and friends) (Nemcova, 2013). According to Svatosova (2012), a situation may occur where it is too late and we are the only witnesses to patient's spiritual distress, terror and fear of the end.

\section{Conclusion}

In the same way as birth, dying is also an integral part of our life. We must realize that dying doesn't only affect biological aspect of life, but also psychological, social and spiritual dimension of a person.

Palliative patient care has recently undergone big changes which respect the natural needs of patients. Our aim was not to judge the work of the nurses and of other medical professionals at the patient care department, but to support improvement of the quality level of assessment and satisfaction of spiritual needs as part of the care. On the basis of the research results, studied publications and our own experience, we would like to propose to continuously increase and expand the knowledge by attending seminars and training on the topics of spiritual needs and taking of spiritual history, to provide information related to current trend development in the assessment of spiritual needs, and to consider financing of courses on accompanying of a dying person organized for nurses and other medical professionals.

Our behavior and the overall approach play a significant role in the quality of a dying patient's last day's experience. Apart from being professionals, we are also people, and those coming to us, apart from being patients, are people too.

\section{References:}

1. ANDRASI I, LITTVA V, SICHMAN M Et Al. (2017) Psychosocial and Spiritual Needs of Dying Patients from the Perspective of the Nurse and Length of Professional Practice. In Clinical Social Work and Health Intervention. Vol. 8 No. 4. p. 7-16. ISSN 2222-386X.

2. BUCK H G, MCMILAN S (2012) A Psychometric Analysis of the Spiritual Needs Inventory in Informal Caregivers of $\mathrm{Pa}$ tients with Cancer in Hospice Home Care. In Oncology Nursing Forum. Vol. 39, No. 4. July. p. 332- 339. ISSN 0190-535X.

3. FARSKY I, ZIAKOVA K, ONDREJKA I (2010) Conceptualization of spirituality. In Nursing research and evidence-based practice. Ed. Sikorova, L, Budzova, R. Ostrava: University of Ostrava. p. 30-36. ISSN 978-80-7368-694-9. 
4. FAULL $\mathrm{CH}$, DE CAESTECKER SH, BLACK F (2012) Handbook of Palliative Care. 3rd edition. New Jersey: John Wiley \& Sons, Inc. Hoboken, P. 364 p. ISBN 9781-118-06559-4.

5. FRANKL V (2010) Palliative care. [Online]. [Cit. 2016-08-27]. Available on: http:// cs.wikipedia.org/wiki/Viktor_Frankl.

6. HAMER D, COPELAND P (2003) Biological basics of human psyche. Praha: Portal, 250 p. ISBN 80-7178-779-5.

7. HASKOVCOVA H (2000) Thanatology, Dying and Death Science. Praha: Galen, 191 p. ISBN 80-7262-034-7.

8. HATOKOVA M Et Al. (2009) Accompanying the sick and the dying. Bratislava: Don Bosco, 215 p. ISBN 978-80-8074-095-5.

9. HERMANN C P (2007) The degree to which spiritual needs of patients near the end of life are met. In Oncol. Nurse Forum. Vol. 34, No. 1, p. 70-78. ISSN 0190-535X.

10. KALVINSKA E (2007) Spiritual care in hospital from the doctor's point of view. Study texts for ETF UK students of the EU pilot project Hospital Chaplain [Online] [Cit. 2012-09- 09].

11. KOBER L (2015) Satisfying the Spiritual needs in Long-Term Hospitalized Patients with End Stage Chronic Disease. In Rev. Int. Sci. Hum. Nat. No.1, p.31 - 58. ISSN 2235-2007.

12. KRIVOHLAVY J (2006) Psychology of meaningful existence. Questions on top of life. Praha: Grada, 204 p. ISBN 80-2471370-5.

13. LUKACKOVA V (2012) Personality and needs of palliative patient. In Florence. Vol. 8, No. 1. ISSN 1801-464X [Online] [Cit. 2018-06-30]. Available on: http://www.flor- ence.cz/odborne-clanky/florence-plus/osobnost-a-potrby-paliativneho- pacienta.

14. MALIKOVA E (2011) Seniors care in residential social facilities. Praha: Grada, 328 p. ISBN 978-80-247-3148-3.

15. MORAUCIKOVAE, LAZAROVAE (2015) Support for bereaved from the perspective of health professionals. In ANDRASI, I. et al. Spiritual Needs of Patients in Palliative Care Martin: Osveta, 122 p. ISBN 978-808063-441-4.

16. MUNZAROVA M (2005) Euthanasia or palliative care. Praha: Grada, 108 p. ISBN 80-247-1025-0.

17. NEMCOVAJ (2013) Selected chapters of palliative nursing care. Multimedia support for teaching clinical and health disciplines. Portal of Jessenius Faculty of Medicine in Martin, Comenius University in Bratislava [Online]. [Cit. 2018-07-18] Available on: <http://portal. jfmed.uniba.sk/clanky.php?aid=237>

18. SHARMA R K, ASTROW A B, TEXEIRA K ET AL. (2012) The Spiritual Needs Assessment for Patients (SNAP): Development and Validation of a Comprehensive Instrument to Assess Unmet Spiritual Needs. Journal of Pain and Symptom Management Vol. 44, No 1, p. 44-51. ISSN: 0885-3924.

19. SLAMA O, KABELKA L, VORLICEK J ET AL. (2007) Palliative medicine for practice. Praha: Galen, 362 p. ISBN 80-7262505-5.

20. STRIZENEC M (2005) Spirituality and its detection. Bratislava: SAV, 12 p. Available on: http:/www.saske.sk/cas/archiv/1-2005/ strizenec.html

21. SVATOSOVA M (2012) Do we know the spiritual needs of the sick? Praha: Grada, 112 p. ISBN 978-80-247-4107-9. 